\title{
Correction to: Characterization of an OrtT-like toxin of Salmonella enterica serovar Houten
}

Luiz Carlos Bertucci Barbosa ${ }^{1} \cdot$ Rodolfo dos Santos Carrijo ${ }^{2} \cdot$ Milena Barbosa da Conceição ${ }^{2}$. Jonatas Erick Maimoni Campanella ${ }^{2} \cdot$ Edson Crusca $^{2}$ - Thais Oliveira Secches ${ }^{1} \cdot$ Maria Celia Bertolini $^{2}$. Reinaldo Marchetto ${ }^{2}$

Published online: 28 June 2019

(C) Sociedade Brasileira de Microbiologia 2019

Correction to: Brazilian Journal of Microbiology https://doi.org/10.1007/s42770-019-00085-3

In the article mentioned above, an author's name was misspelled.

The correct author name reads as follows:

Edson Crusca

We apologize for the inconvenience.

The online version of the original article can be found at https://oi.org/ 10.1007/s42770-019-00085-3

Luiz Carlos Bertucci Barbosa

lcbertucci@gmail.com

1 Institute of Natural Resources, Federal University of Itajubá, BPS, 1303, Bairro Pinheirinho, Itajubá, MG 37500-903, Brazil

2 Institute of Chemistry, São Paulo State University, Araraquara, SP, Brazil 